\title{
Especialistas e Políticas: As audiências públicas do novo Código Florestal
}

\author{
Expertise and Policy: Public Hearings of the Brazilian Forest Code
}

Jean Carlos Hochsprung Miguel ${ }^{1}$

Léa Velho ${ }^{2}$

Artigo recebido para publicação em Ago/2013 e aceito para publicação em Set/2013.

\section{RESUMO}

Este artigo discute a participação de especialistas em processos de tomada de decisão através de um estudo das audiências públicas realizadas pelo Congresso Nacional Brasileiro para a reformulação do Código Florestal. Através da análise dos discursos de parlamentares e especialistas nessas audiências, argumenta-se que nesses espaços o status dos especialistas, bem como seus conhecimentos, são constantemente negociados entre os participantes parlamentares e os próprios especialistas - no decorrer das discussões. Desse modo, tal processo de "construção e desconstrução" das expertises nesses ambientes é apresentado como um desafio a ser enfrentado pela tão necessária ampliação das discussões públicas para tomada de decisão em temas que requerem a opinião de especialistas.

Palavras-chaves: Tomada de decisão. Expertise. Estudos da Ciência e da Tecnologia.

\section{ABSTRACT}

A challenge to democratic societies is how to integrate expert advice into decision making processes and policy formulation. The analysis of the process of expert counseling becomes even more important due to the fact that the definition of who is an expert in a particular topic is already the product of political arrangements. This paper

tackles this issue by analyzing the hearings held by the Brazilian National Congress from 2009 to 2012, to inform the reformulation of the Brazilian Forest Code. By taking up the discourse of the experts as registered in the hearings notes the paper argues that in public arenas the expertises are constantly negotiated between the participants - member of parliament and experts - during the discussions. The process of "construction and deconstruction" of expertise in these environments is a challenge to the much needed expansion of public participation in decision making on issues that require expert advice.

Keywords: Public hearings. Brazilian forest code. Expert advice; Decision making.

\footnotetext{
1 Sociólogo, Doutorando em Política Científica e Tecnológica, Instituto de Geociências, UNICAMP, jeanchm@ige.unicamp.br

2 Professora Titular do Departamento de Política Científica e Tecnológica, Instituto de Geociências, UNICAMP, velho@ige.unicamp.br
} 


\section{INTRODUÇÃO}

Um desafio lançado às sociedades democráticas na atualidade é como incorporar nos processos de tomada de decisão e formulação de políticas o aconselhamento de especialistas. Dedicados a essa questão, autores do campo dos Estudos Sociais da Ciência, Tecnologia e Sociedade (ESCT) tem indicado que o processo de aconselhamento científico da decisão política não é uma via de mão única que vai do conhecimento objetivo e consensual da ciência ao meio ideológico e conflituoso da política, mas um processo contínuo de entrelaçamento de políticas e expertises ${ }^{1}$, uma relação de envolvimento, marcada por disputas que perpassam esses campos e os redefinem mutuamente (NELKIN, 1979, GIERYN, 1983; JASANOFF, 1987; 1990; RIFKIN e MARTIN, 1997, NOWOTNY, 2000).

Demonstrar as diferentes relações entre a ciência e a política em diferentes contextos e espaços pode trazer contribuições importantes para tornar mais claro os processos pelos quais diferentes atores sociais e diferentes formas de conhecimento modelam a tomada de decisão política. Jasanoff $(1986,1995)$ documenta empiricamente que o modo como especialistas são incluídos nas tomadas de decisão varia consideravelmente de país para país. Assim, estudos de caso podem elucidar as diferentes formas que políticos aceitam certos tipos de evidências defendidas por especialistas e como certas informações são incorporadas nos discursos para sustentar posições políticas.

No atual contexto político brasileiro, o caso da reelaboração do Código Florestal que tramitou no Congresso Nacional foi marcado por disputas em torno das propostas dos deputados da bancada ruralista que pretendiam alterar os critérios de demarcação e recomposição de Reservas Legais (RL) e Áreas de Preservação Permanentes (APP's). Essa iniciativa de reforma do Código devia-se ao fato de que grande parte das propriedades rurais se encontrava na ilegalidade perante as leis florestais. Sem querer abrir mão da produção existente em áreas de preservação, os

\footnotetext{
${ }^{1}$ Expertise é uma palavra inglesa que significa aptidão, perícia ou habilidade para determinada tarefa. Nos ESCT, o termo é utilizado não somente para se referir ao conhecimento técnico-científico, mas a um leque mais amplo de conhecimentos tácitos (ou não) que podem ser utilizados como fonte de informação no processo político de tomada de decisão. Também é preciso esclarecer que os termos especialista e expert serão utilizados de forma intercambiável ao longo do texto para se referir aos atores que têm sua expertise reconhecida e são considerados "aqueles que devem ser ouvidos" a respeito de algum assunto nas decisões públicas. Essa noção bastante ampla do termo será problematizada na unidade seguinte.
} 
ruralistas retomaram a discussão de um antigo projeto de lei (PL1876/99) que tinha como principal proposta a consolidação das áreas produtoras consideradas ilegais e o cancelamento de multas aplicadas aos produtores rurais por descumprimento do Código. Estas propostas foram chamadas pelos opositores da bancada de "anistia" dos crimes ambientais e culminaram em uma luta política que, dentre outros espaços, teve como arena as audiências públicas realizadas pelo Congresso.

Para essas audiências foram convidados especialistas que deveriam apresentar suas opiniões sobre os seguintes aspectos: quais parâmetros técnicos podem orientar a redefinição das medidas das RL's e APP's no novo Código e como recompor essas áreas quando ocupadas com produção agropecuária sem que ocorra a queda na produção de alimentos.

Com base nas transcrições das 46 audiências realizadas entre 2009 e 2012, este artigo busca responder três questões: a) Como ocorreu a inclusão e a participação de especialistas nessas audiências? b) Qual papel foi atribuído pelos parlamentares aos porta-vozes da comunidade acadêmica? c) Como foram mobilizadas as informações dos especialistas nesse processo para sustentar diferentes posições políticas?

Inicia-se com uma discussão sobre o aconselhamento especializado da política e da própria noção de especialista e expertise com base na literatura dos Estudos Sociais da Ciência e da Tecnologia (ESCT). Argumenta-se sobre o caráter socialmente localizado da expertise científica e as limitações da mesma em produzir aconselhamento inequívoco para solução de problemas, mesmo quando esses são de "natureza técnica". Um dos motivos para isso é que, nas discussões públicas contemporâneas, a capacidade de argumentação lógica e a objetividade do conhecimento representado pelos cientistas não são, por si só, a fonte do poder e do reconhecimento do status de expert, pois este status depende do uso e da valorização das informações por parte dos tomadores de decisão e demais atores envolvidos. Assim, os arranjos e estruturas de tomada de decisão podem utilizar certas expertises e ignorar outras, independente do status que thes é reconhecido por grupos especializados fora das arenas públicas.

Por outro lado, os tomadores de decisão nos regimes democráticos dependem das informações trazidas pelos especialistas para legitimar suas decisões. Em casos como o do Código Florestal, que envolvem questões ambientais 
e interesses econômicos que permitem argumentação de ordem técnica, a participação de especialistas torna-se um imperativo para a legitimidade do processo legislativo. Nessas condições, a organização de audiências públicas surge como um instrumento estratégico que possibilita trazer o público em geral e especialistas para a deliberação no processo decisório.

$\mathrm{Na}$ segunda sessão, apresentam-se as propostas da bancada ruralista que deram origem às controvérsias e como ocorreu a seleção de especialistas para participarem da discussão nas audiências. Indica-se que a prerrogativa política dos parlamentares na escolha dos especialistas representa um primeiro momento da negociação para delimitar previamente em quais áreas do conhecimento e atuação profissional seriam concentradas as discussões. Argumenta-se que nessa fase do processo político houve um fator estratégico importante de seleção e delimitação de "fronteiras" que incluiu determinados tipos de expertises nas audiências públicas e ignorou outros.

Na terceira sessão o foco da análise se dirige à construção pública do status dos especialistas nas audiências. No decorrer dos debates sobre o Código Florestal, os pesquisadores da EMBRAPA foram alguns dos atores mais reivindicados pelos parlamentares e demais participantes como "aqueles que deveriam ser ouvidos" a respeito das questões agroflorestais. Ao analisar a participação desses especialistas, revela-se como as informações e o status desses atores foram objeto de negociações ao longo das audiências. Para tanto, são apresentados alguns trechos das conversações nas quais foram discutidos dois assuntos que dividiram as opiniões de tomadores de decisão e especialistas. O primeiro referia-se à possível queda da produção de alimentos caso fosse exigido o cumprimento estrito das leis florestais. O segundo tratava da definição dos limites nacionais para as Áreas de Preservação Permanentes (APP's) e da proposta de descentralização das leis florestais. Nas discussões de ambas as controvérsias, os especialistas da EMBRAPA, que inicialmente foram chamados na condição de experts, passaram a ser questionados por tomadores de decisão e especialistas contrários às suas propostas. Ao analisar esses embates, indica-se que ocorreram disputas pela autoridade do expert na discussão dos dois assuntos mencionados. Como consequência desses embates, rompeu-se a pretendida demarcação entre tomadores de decisão e especialistas no processo de aconselhamento. 
Através do estudo de caso do Código Florestal sugere-se que a definição de alternativas políticas está relacionada a uma luta pela indicação política de determinadas expertises. Todavia, nas arenas públicas, tais expertises indicadas participam do jogo político no processo deliberativo e são sujeitas a constantes negociações. Nesse sentido, uma análise de processos políticos que pretende entender as reais dificuldades da incorporação de conhecimentos nas decisões públicas não pode prescindir da compreensão do modo como os especialistas participam dessas disputas.

\section{PROCESSO DE TOMADA DE DECISÃo E ACONSELHAMENTO ESPECIALIZADO}

De maneira geral, supõe-se que os tomadores de decisão recorrem aos especialistas por duas razões fundamentais. Primeira, eles usam a expertise para tornar suas decisões mais razoáveis, justificáveis e efetivas. Segunda, porque o uso da expertise gera uma decisão com maior crédito e aceitação pública (BROWN et. al., 2005). Além disso, é possível pensar que buscar conselhos especializados é um imperativo na tomada de decisões em condições que envolvem riscos, conflitos de interesses, incertezas e questões morais e éticas (BECK, 2010; HASS, 1992; MORIN, 1999).

Nas sociedades ocidentais modernas do início do século XX, a questão de como ocorreu a estruturação, a diferenciação e a distribuição do poder em diferentes subgrupos com valores, orientações e conhecimentos específicos, já configurava um problema para sociólogos como Max Weber (1920), que reconheceu neste processo um sentido negativo da organização cada vez mais racional e burocratizada da sociedade. A partir de 1950, esse processo de especialização e expansão da burocracia preocupou muitos outros autores que pensaram nas influências que isso teria aos valores políticos da democracia (LAKOFF, 1966; MEYNAUD, 1969; MARCUSE, 1979; NELKIN, 1979). Perpassando um grande conjunto de questões, a ameaça da tecnocracia se tornou um dos problemas centrais das discussões desses autores sobre a participação de especialistas nos processos políticos democráticos. 
Segundo Weingart (2005), já na década de 1960, os parâmetros e suposições básicas desse debate mudaram em decorrência de três principais alterações que afetaram a relação entre a expertise científica e os arranjos políticos nos países da Europa Ocidental e nos Estados Unidos.

A primeira referiu-se a alguns aspectos do sistema político. Desde a década de 1960, esses países tiveram uma rápida expansão democrática que se tornou visível na emergência de movimentos políticos que operaram fora do sistema das instituições formais, tais como os movimentos antinuclear e ambientalista. Isso ensejou novas formas de participação pública e novos mecanismos de discussão entre tomadores de decisão e cidadãos.

A segunda mudança ocorreu com a ciência. Como resultado das transformações políticas mencionadas, passou-se a questionar a imparcialidade e a objetividade do conhecimento científico como suporte para as decisões políticas. $O$ fato de que os experts apareciam defendendo posições em ambos os lados das controvérsias públicas suscitou a ideia de que o conhecimento científico não é inequívoco e desinteressado e que, portanto, seus representantes inserem-se no jogo político como players.

A terceira dizia respeito à relação entre a ciência, a política e a sociedade de um modo geral. A maior democratização, a desmistificação do conhecimento científico e a mudança para uma nova administração pública naqueles países resultaram em novas exigências à comunidade científica. Passou-se a exigir que as instituições científicas prestassem contas sobre os gastos públicos investidos em pesquisas e demonstrassem as eventuais utilidades sociais dos conhecimentos produzidos.

Para Weingart (2005), essas três mudanças que ocorreram nos países da Europa Ocidental e nos Estados Unidos provocaram a "democratização da expertise científica", implicando em uma redefinição da própria noção de expertise que, para além do conhecimento científico, passou a abarcar uma maior variedade de atores e seus respectivos tipos de conhecimentos considerados relevantes para 0 aconselhamento das decisões públicas.

Ao discutir esse fenômeno da distribuição social da expertise, a socióloga Helga Nowotny (2000) observou que a competência para essa função já não está incorporada na matriz estrutural centralizada das universidades e demais institutos 
de pesquisa, mesmo que ainda exista um entendimento geral de que as decisões políticas que envolvem aspectos de elevado grau técnico devam ser guiadas por cientistas. Segundo ela, há uma nova configuração social na qual empresas, organizações não governamentais, associações civis, dentre outras instituições passam a ter sua competência socialmente reconhecida na produção de conhecimento válido. Nesse sentido, a expertise passou a ser reconhecida como uma competência que transgride os parâmetros do conhecimento científico, tornando-se "uma configuração fluida de informação, conhecimento e experiência situada" (NOWOTNY, 2000, p. 12).

A distribuição social da expertise refletiu no fato de que os tomadores de decisão necessitam cada vez mais do aconselhamento de especialistas devido às três razões anteriormente mencionadas: tornar suas decisões mais razoáveis, legitimar publicamente suas decisões políticas e tomar decisões em condições de complexidade e incerteza. Entretanto, nessa relação, os alinhamentos entre experts e políticos adquirem uma maior variedade de formas, cujos padrões já não refletem mais a configuração pretendida pelo positivismo, na qual somente a ciência moderna poderia falar a verdade ao poder.

Nas novas condições apresentadas, o aconselhamento especializado da política depende de "como" e de "quem" os arranjos políticos selecionam e valorizam como expert. Como observou Gieryn (1983), esse processo nas tomadas de decisão frequentemente transforma-se em uma disputa para circunscrever linhas divisórias que pretendem separar conhecimentos válidos e não válidos a respeito das controvérsias em questão. Esse trabalho de "desconstruir e reerguer fronteiras" entre as expertises relevantes e as consideradas de menor importância para os assuntos discutidos é reconhecido pelo autor como uma característica dos processos políticos contemporâneos. Um aspecto desse processo que foi destacado por Jasanoff (1987; 1990) é que tais linhas divisórias, frequentemente, acabam sendo "borradas" e confundem as propostas políticas e os conhecimentos alistados para aconselhá-las. De um modo geral, esse trabalho político de delimitação apontado por estes autores permite perceber que a valorização de determinada expertise não advém automaticamente de suas capacidades intrínsecas, mas depende de um processo social de persuasão e contestação da validade de tais conhecimentos. 
Também Rifkin e Martin (1997) observaram que nas discussões públicas, nas quais comunicam-se tomadores de decisão, especialistas e público, há uma constante negociação do status dos experts. Segundo os autores, isso corresponde a uma "construção social do papel do especialista pelos participantes na conversação" (Idem, p. 30). Nesses ambientes, o privilégio de ser considerado um especialista em algum assunto não depende somente da profissão ou da carreira dos atores envolvidos, mas também de fatores como o grupo para o qual se está falando, a instituição a que pertence, a natureza das questões em debate e do resultado da discussão face a face. Portanto, a atribuição de uma autoridade expert em uma conversação não é pré-ordenada, mas negociada, como resultado de um processo "iterativo e interativo" (Ibidem, p. 33).

Nota-se, portanto, que analisar a negociação do conhecimento nos processos políticos deliberativos é de grande relevância para estudos dedicados à compreensão desses processos em decisões públicas. Além de possibilitar a compreensão das disputas de valores, interesses e ideologias nos debates políticos, esses estudos também possibilitam a compreensão dos conflitos criados pelos diferentes tipos de conhecimentos que, conforme Foucault (1982, p.82) enfatizou, estão "implicados a toda forma de poder".

Nessa perspectiva, dirigir o foco da análise para os processos de aconselhamento de especialistas em espaços públicos pode servir para identificar uma variedade de alinhamentos entre especialistas e tomadores de decisão em relação às controvérsias discutidas. Através dessa análise, indica-se que a realidade do processo de aconselhamento expert da política não se presta a qualquer generalização, pois cada caso pode se revelar singular e complexo.

No estudo de caso que será apresentado, investigam-se as audiências públicas do Código Florestal atentando para as singularidades das discussões que ocorreram no atual contexto da democracia brasileira. Entende-se que no Brasil os processos políticos possuem uma forma e uma dinâmica próprias, permeadas por particularidades da história e da cultura política local. Portanto, apesar desta sessão ter discutido o problema do aconselhamento expert através de autores que dirigiram suas análises às sociedades industriais dos países do hemisfério norte, buscou-se pensar perspectivas de análise sem pretender sugerir a proximidade dos contextos históricos e políticos. Nesse sentido, a discussão do caso a seguir não se presta, 
nesse momento, à comparação, mas pretende apontar e problematizar aspectos da interação entre tomadores de decisão e especialistas em audiências públicas que ocorreram na realidade política do Congresso Nacional Brasileiro.

\section{AFINAL, QUEM DEVE SER OUVIDO? A SELEÇÃO DE ESPECIALISTAS PARA AS AUDIÊNCIAS PÚBLICAS DO CÓDIGO FLORESTAL}

A realização das 46 audiências públicas para discutir a reelaboração do Código Florestal aconteceu em um momento definitivo da tramitação do Projeto de Lei (PL) 1.876 de 1999 na Câmara dos Deputados Federais e no Senado². Neste projeto, estavam reunidas as principais propostas feitas pela Frente Parlamentar Agropecuária (FPA) para a alteração do Código Florestal.

De forma simplificada, os pontos mais controversos dessa proposta eram:

a) A supressão dos limites previstos para as APP's em nível federal, passando sua determinação para os estados e municípios ${ }^{3}$;

b) A redução da porcentagem das Reservas Legais (RL's) nas regiões da Amazônia e do Cerrado ${ }^{4}$;

c) A proposta de consolidação das áreas produtoras ilegais até 22 de julho de $2008^{5}$.

Essas propostas atendiam, principalmente, as reivindicações dos proprietários de imóveis rurais que estavam na ilegalidade. Apesar disso, ao longo de dez anos

\footnotetext{
${ }^{2}$ No Senado, o PL 1.876/99 recebeu o número 30/2011. Neste estudo, refere-se ao projeto apenas pela sua numeração da Câmara.

${ }^{3}$ Áreas de Preservação Permanente (APP's), segundo o Código Florestal (Lei 4.771/65), são aquelas que estão em locais que representam tensões ecológicas, tais como margens dos rios, topos e encostas de morros, mangues, dentre outras. Para estas áreas que apresentam fragilidades quando desguarnecidas da vegetação nativa, o Código estabelece medidas obrigatórias nas propriedades rurais. Por exemplo: 30 metros de vegetação nativa nas margens dos cursos d'água com até 10 metros de largura.

${ }^{4}$ Além das APP's, as Reservas Legais (RL's) são outra parcela das propriedades rurais que devem ser mantidas com vegetação nativa. $O$ tamanho destas áreas varia conforme o bioma em que estão localizadas. Nas regiões da Amazônia, devem ser de $80 \%$, no Cerrado 35\% e nas demais regiões $20 \%$. O PL 1876/99 pretendia reduzir para 50\% a porcentagem na Amazônia e para todas as demais regiões estabelecia $20 \%$.

${ }^{5}$ Essa proposta foi chamada pelos ambientalistas de "anistia", pois, segundo eles, traduz-se em um "perdão" dos crimes ambientais cometidos. A data 22 de julho de 2008 é referente à publicação do Decreto 6.514 que versa sobre as infrações e sanções administrativas aos crimes ambientais cometidos e exige a averbação dos imóveis rurais prevendo a possibilidade de embargo das áreas desmatadas ilegalmente.
} 
de tramitação do projeto na Câmara, não foram obtidos resultados favoráveis à sua aprovação. Devido ao volume jurídico crescente e à pressão da bancada ruralista para dinamizar a tramitação, a presidência da Câmara, em 8 de setembro de 2009, criou uma Comissão Especial para produzir um parecer definitivo sobre o projeto.

A Comissão Especial foi presidida por um dos membros da bancada ruralista, o deputado federal Moacir Michelleto (PMDB/PR), e teve como relator o deputado federal Aldo Rebelo (PCdoB/SP), que era favorável às propostas ruralistas. Através dessa comissão parlamentar, foram realizadas 14 audiências públicas internas à Câmara dos Deputados Federais e 20 audiências públicas externas em 15 estados brasileiros. Somadas a essas 34 audiências, outras 12 foram realizadas pelo Senado em 2011 quando a matéria passou a ser discutida na Casa.

É importante destacar que os regimentos internos das duas Casas legislativas do Congresso informam que a organização de audiências públicas tem a função de instruir matérias legislativas em trâmite ou debater assuntos de interesse público relevante. No regimento interno da Câmara dos Deputados Federais, em seu capítulo 3, Art. 256, especifica-se que "aprovada a reunião de audiência pública, a Comissão selecionará, para serem ouvidas, as autoridades, as pessoas interessadas e os especialistas ligados às entidades participantes".

Entretanto, apesar de serem espaços abertos ao público, as audiências são organizadas de forma que se prioriza a fala dos parlamentares e especialistas convidados. Conforme seu padrão oficial, estas reuniões são iniciadas com a fala do parlamentar que preside a mesa. Este apresenta os convidados que serão ouvidos segundo uma ordem de inscrição previamente organizada. Em média, a fala dos convidados é limitada em 15 minutos para as audiências externas e 30 minutos para as internas. Posteriormente, passa-se o microfone aos parlamentares inscritos e depois ao público ${ }^{6}$.

A seleção dos convidados é uma prerrogativa dos parlamentares. Esta seleção ocorre através da submissão de requerimentos dirigidos à mesa da Presidência da Comissão competente. Normalmente, a aprovação ou rejeição dos requerimentos emitidos é submetida à votação dos membros da comissão. Após

\footnotetext{
${ }^{6}$ É importante destacar que na maioria das ocasiões, políticos e técnicos ocuparam com suas falas a maior parte do tempo das audiências, enquanto o tempo conferido ao público foi notadamente mínimo.
} 
aprovados, são emitidas cartas oficiais aos convidados e estes são livres para aceitar ou não o convite.

No caso da Comissão Especial da Câmara que discutiu a matéria do Código Florestal, houve um acordo para que nenhum requerimento dirigido à mesa fosse rejeitado ${ }^{7}$. Assim, esse acordo possibilitou 0 acirramento da luta política nas audiências públicas entre uma grande variedade de atores indicados pelos parlamentares como "aqueles que devem ser ouvidos" a respeito das questões relacionadas ao Código Florestal. Desse modo, os convites que foram feitos pelos tomadores de decisão podem ser interpretados como uma seleção de diferentes tipos de expertises para os debates.

Ao analisar os requerimentos emitidos pelos parlamentares para a escolha dos convidados, percebe-se que o alistamento de determinadas expertises para o aconselhamento dos assuntos debatidos refletiu a orientação política e 0 compromisso dos tomadores de decisão com determinadas bases ${ }^{8}$. Se por um lado parlamentares da bancada ruralista convidaram especialistas que, em sua maioria, tinham relação com o setor de produção e pesquisa agropecuária, por outro os partidos da oposição à bancada escolheram majoritariamente especialistas comprometidos com causas preservacionistas. Assim, a polarização das posições políticas entre ruralistas e ambientalistas informou as escolhas dos especialistas convidados.

Além de demonstrar que o alistamento de especialistas ocorreu através de determinadas orientações e compromissos políticos, a análise dos requerimentos emitidos revelou que a expertise listada para os debates nas audiências públicas incluía uma grande variedade de atores considerados especialistas pelos tomadores de decisão. Este conjunto diversificado de experts contou com doutores em Ciências Naturais e Agrárias, representantes de Confederações da Agricultura, prefeitos de municípios que apresentavam casos considerados pertinentes às discussões, representantes de ONG's ambientalistas, Ministros da Agricultura e do Meio Ambiente, doutores em Direito, promotores, dentre outros. Esse aspecto do caso

\footnotetext{
7 Esta declaração foi feita pelo presidente da Comissão Especial deputado Moacir Micheletto (PMDB/PR) em audiência pública interna realizada em 03 de novembro de 2009: "No início dos trabalhos, fizemos um acordo no sentido de que aprovaríamos todo e qualquer requerimento". De fato, não consta entre os 88 requerimentos emitidos nenhum que tenha sido rejeitado.

8 Para a análise detalhada dos requerimentos ver Miguel (2013, p. 44).
} 
indicou que a condição de distribuição social da expertise marcou a seleção dos especialistas para as audiências, pois a capacidade de fornecer conhecimento válido foi atribuída a uma ampla variedade de atores, dentre eles a expertise científica (NOWOTNY, 2000; WEINGART, 2005).

Entretanto, isso não significa que, no decorrer dos debates, a "Ciência" como autoridade epistêmica não tenha sido reivindicada para discutir certos assuntos. Como observou Nowotny (2000), apesar do fato da expertise encontrar-se distribuída socialmente, ainda há uma forte narrativa de maior valoração do conhecimento científico nas tomadas de decisão. No entanto, conforme argumentado na sessão anterior, a "Ciência" reivindicada no processo de decisão pública não efetiva o modelo de tomada de decisão do positivismo, no qual seria capaz de falar a verdade ao poder de forma direta e incontestável. Isso porque a participação de cientistas nas discussões públicas ocorre em condições marcadas pelos efeitos de negociações constantes.

Para ilustrar como esse processo de negociação da expertise ocorreu nas audiências públicas do Código Florestal, em seguida analisam-se discussões sobre as duas controvérsias que envolveram tomadores de decisão, pesquisadores da EMBRAPA, dentre outros atores presentes. Destaca-se como, no desenrolar das conversações, a construção e a contestação do status científico dos pesquisadores da EMBRAPA fez parte do processo político. Para isso foram lidas e analisadas notas taquigráficas de 46 audiências públicas realizadas entre 2009 e 2012. Buscouse nessa leitura atentar para os diferentes posicionamentos que os participantes adotavam em seus discursos em relação às controvérsias.

\section{CONSTRUÇÃO E CONTESTAÇÃO DO STATUS CIENTíFICO NAS AUDIÊNCIAS PÚBLICAS: O CASO DOS PESQUISADORES DA EMBRAPA}

A reivindicação para que as discussões sobre os limites e os possíveis usos das APP's e das RL's ocorressem através de argumentos técnicos e científicos fez parte dos discursos da maioria dos atores que participaram das audiências públicas. Tanto atores ligados ao setor agropecuário quanto representantes da causa ambientalista concordaram com a necessidade de trazer a "Ciência" para o debate: 
Um dos pontos que concordamos na questão do Código Florestal e que acho que vale a pena ser ressaltado é o ponto de que todas as vezes que tivermos divergências, os ecologistas tiverem divergência com os produtores, e que houver a possibilidade do arbítrio da ciência, colocaremos a ciência como árbitro, resolveremos as questões através da ciência (Dep. Fernando Gabeira - PV/RJ. Audiência pública da Câmara, 26/11/2009).

Percebo que estamos caminhando para uma convergência muito grande. Vi aqui, nas exposições dos representantes da ANA, do Greenpeace e do Instituto Socioambiental que, se aprofundarmos um pouco mais as coisas no sentido de buscar a academia como sustentação para decisão política e acredito que ninguém discorde disso -, vão restar poucas divergências; vamos chegar a um ponto fundamental para mudar conceitos (Dep. Paulo Piau - PMDB/MG. Audiência pública da Câmara, 26/11/2009).

Como pode ser observado nas falas do líder do Partido Verde (PV), Fernando Gabeira, e do presidente da Frente Parlamentar Agropecuária (FPA) no Sudeste, Paulo Piau, delegar aos pesquisadores a tarefa de resolver questões relacionadas aos parâmetros e aos usos das áreas de preservação seria uma forma de afastar as ideologias e interesses particulares dos debates do caso em questão. Dessa maneira, transmitiu-se a mensagem de que laudos técnicos sobre as particularidades do solo, clima, condição dos rios e da floresta seriam a melhor forma de romper o dualismo entre preservar a natureza e avançar na produção de gêneros agrícolas. Nesse sentido, elabora-se no discurso uma fronteira que, segundo eles, deve ser mantida na discussão das APP's e das RL's. Tal fronteira pretende dividir saberes considerados técnicos e não técnicos, conferindo aos primeiros a prerrogativa de informar os objetivos políticos e a capacidade de produzir consenso.

Ao enunciarem a prerrogativa da expertise científica quanto à definição de parâmetros para as APP's e RL's, os tomadores de decisão frequentemente elegiam em suas falas especialistas e instituições que julgavam competentes para exercer esta tarefa. Dentre eles, os pesquisadores e os trabalhos da EMBRAPA foram os mais citados como capazes de tratar adequadamente os assuntos técnicos relacionados à agricultura e à questão ambiental.

Um fato que ilustra esse reconhecimento é que o número de especialistas da EMBRAPA convidados para os debates foi superior ao das demais instituições. Houve até mesmo uma audiência pública (em 29/03/2010), realizada pela Comissão 
Especial da Câmara na sede da EMBRAPA - Floresta no Paraná ${ }^{\text {. Esse }}$ reconhecimento da competência da EMBRAPA nas audiências, em grande parte, ocorreu nos discursos dos ruralistas, como pode ser observado nas seguintes falas:

Seria importante que a EMBRAPA, na defesa do setor primário do nosso país, pudesse tentar medir esses impactos e tentar estabelecer aqui o bom confronto entre a pesquisa, entre a ciência, que é gerada pela EMBRAPA, com os outros segmentos. (Dep. Homero Pereira - PSD/MT. Audiência pública da Câmara, 08/12/2009).

Tudo o que nós estamos contestando aqui, tudo o que nós queremos mudar não é pelo discurso, não é pela emoção, é, sim, por parâmetros técnicos da nossa comunidade científica, da nossa EMBRAPA. (Dep. Moacir Micheletto - PMDB/PR. Audiência pública da Câmara, 11/12/2009).

Eu abomino quem chega aqui e desprestigia a EMBRAPA. É o maior centro de pesquisa tropical do mundo e, portanto, tem de ser respeitada. E não é o parecer de uma ONG internacional que desprestigia e desmerece um parecer de um técnico da EMBRAPA. Portanto, nós achamos que toda condição deve ser feita em cima de bases técnicas, científicas. (Márcio Lopes de Freitas - Presidente da Organização das Cooperativas Agrícolas Brasileiras. Audiência pública da Câmara, 03/02/2010).

Trinta e cinco anos de EMBRAPA é para se ouvir de cabeça baixa o que a EMBRAPA tem para ensinar. (Dep. Ernandes Amorim - PTB/RO. Audiência pública da Câmara, 10/11/2009).

Como se pode notar nas falas anteriores, os ruralistas apontaram a EMBRAPA como a única instituição de pesquisa capaz de conduzir de forma objetiva e imparcial a resolução das controvérsias políticas. No entanto, destaca-se que o reconhecimento da competência da EMBRAPA também ocorreu na fala de opositores à bancada ruralista, porém com menor ênfase em sua exclusividade:

O Brasil tem massa crítica para elaborar essa legislação. A EMBRAPA é uma instituição conhecida por todos nós, que tem tecnologia. O Instituto Nacional de Pesquisas Espaciais (INPE) provavelmente detém o maior cabedal de tecnologia de monitoramento de satélite. Há universidades brasileiras, a ESALQ, a Universidade Federal do Paraná, dentre outras. (Fábio Feldmann - Ambientalista cofundador da ONG SOS Mata Atlântica. Audiência pública da Câmara, 12/11/2009)

Os dados que usamos no Ministério são de instituições de renome. Dados do desmatamento na Amazônia são do INPE, uma instituição séria, internacionalmente reconhecida, muito técnica. Quanto ao custo de recuperação de área degradada são dados da EMBRAPA. (Carlos Minc Ministro do Meio Ambiente. Audiência Pública da Câmara, 24/11/2009).

Sobre estudos de sistemas agrossilvopastoris são de grande relevância as pesquisas da EMBRAPA Meio Ambiente. Sugiro aos senhores (Deputados) que também explorem bastante o Dr. Paulo Kageyama da ESALQ-USP, ele trabalha há anos com agricultura familiar em sistemas agroflorestais para

\footnotetext{
${ }^{9}$ Dos 30 representantes de instituições de pesquisa que participaram das audiências públicas 12 eram da EMBRAPA, dos quais 6 da EMBRAPA Florestas (MIGUEL, 2013, p.92).
} 
recuperação de RL's e APP's. (Luiz Henrique Gomes de Moura Representante da Articulação Nacional de Agroecologia. Audiência pública da Câmara, 26/11/2009).

Observa-se que os opositores da bancada ruralista, ao destacarem a importância da EMBRAPA no processo, citaram a empresa em meio a outras instituições consideradas de igual importância. Já nas falas dos ruralistas, essa diversidade não foi encontrada. Isso indica que, apesar de reconhecerem a prerrogativa da expertise científica e da importância da EMBRAPA nos assuntos de caráter técnico, ruralistas e ambientalistas possuem expectativas diferentes sobre quais instituições e quais especialistas devem ser ouvidos. No desenrolar dos debates, essa diferença foi evidenciada, principalmente na discussão de duas das principais controvérsias em questão: a primeira, sobre a possível queda da produção de alimentos, caso haja a aplicação estrita do Código Florestal que foi traduzida na proposta de consolidação das áreas produtoras ilegais; e a segunda, sobre a definição dos limites nacionais para as APP's, que suscitou a proposta de descentralização das leis ambientais.

\subsection{A CONTROVÉRSIA DA QUEDA NA PRODUÇÃO DE ALIMENTOS}

O problema apontado pelos ruralistas, de que ocorreria uma queda na produção agropecuária se o que determinam as leis florestais fosse cumprido estritamente, embasava-se nos trabalhos da EMBRAPA - Monitoramente por Satélite, indicado nas discussões como sendo de responsabilidade do pesquisador Evaristo Miranda. Esses trabalhos localizaram, através de imagens obtidas por satélite, grandes extensões de APP's ocupadas com produção agrícola em todo o território nacional. Esse dado foi utilizado diversas vezes pelos ruralistas para justificar a necessidade de consolidar as áreas produtoras ilegais:

Conforme o trabalho feito pelo Dr. Evaristo da Embrapa, teremos de entregar 50 milhões de hectares que hoje estão produzindo no Brasil. (Dep. Luis Carlos Heinze - PP/RS. Audiência pública da Câmara, 12/11/2009).

Se eu aplicar a legislação do Código Florestal como ele existe hoje, o Nordeste só teria $57,93 \%$ de sua área para desenvolvimento de lavouras, cidades, infraestrutura e todas as outras atividades, mineração e qualquer coisa. Este é um estudo da EMBRAPA, sob a responsabilidade do Dr. Evaristo Miranda (Nelson Ananias Filho - Representante da CNA). Audiência pública da Câmara, 14/11/2009). 


\begin{abstract}
O trabalho de Evaristo Miranda da Embrapa não tem erro, é um trabalho técnico, é um trabalho científico, é um trabalho bem feito sobre o impacto da legislação ambiental sob o ponto de vista da ocupação do território nacional (Reinhold Stephanes - Ministro de Estado da Agricultura, Pecuária e Abastecimento - MAPA. Audiência Pública da Câmara, 08/12/2009).
\end{abstract}

Tais afirmações fazem crer que a expertise científica do pesquisador da EMBRAPA - Monitoramento por satélite tornava plausível a proposta de consolidação das áreas produtoras ilegais, pois a exigência de sua recomposição representaria perda econômica irreparável. Nesse sentido, no decorrer desses discursos, o status conferido ao pesquisador e à instituição garantiram robustez à proposta de consolidar as vastas áreas consideradas ilegais.

Entretanto, para aqueles que interpretaram a proposta de consolidação como uma "anistia" aos crimes ambientais cometidos, as pesquisas de Evaristo Miranda não foram admitidas como evidência. $O$ ambientalista Fábio Feldmann, por exemplo, destacou que "mesmo dentro da EMBRAPA há polêmica sobre os dados do Evaristo Miranda" e sua possível relação com a queda da produção de alimentos (audiência pública da Câmara, 12/11/2009). Também Cristina Godoy de Araújo Freitas, coordenadora da área de meio ambiente do Ministério Público, informou que "o estudo de Evaristo Miranda já foi contestado e desqualificado por pesquisadores como Paulo Kageyama da ESALQ/USP" ${ }^{10}$ (audiência pública da Câmara, 03/02/2010). Embasados nas expertises de outros especialistas, tanto Feldmann quanto Freitas concordaram que não havia como inferir, das pesquisas de Evaristo Miranda, uma relação entre a exigência de recomposição e a queda da produção de alimentos.

Portanto, observa-se na discussão dessa controvérsia a efetiva negociação social do status dos especialistas e de suas informações pelos participantes da conversação. Se para os ruralistas o Dr. Evaristo Miranda deve receber toda a credibilidade a respeito dos dados de sua pesquisa, para os ambientalistas há controvérsias que descaracterizam o trabalho do pesquisador como "prova" de que a aplicação das leis florestais causarão a queda da produção de alimentos. Nesse sentido, ambas as partes, ao buscarem fortalecer suas posições políticas através da

\footnotetext{
${ }^{10}$ Paulo Kageyama é professor de ESALQ/USP. Desenvolve pesquisas sobre aspectos políticos, científicos e técnicos para proteção, restauração e uso sustentável dos recursos naturais e das matas ciliares no estado de São Paulo. Foi diretor do departamento de conservação da biodiversidade, do Ministério do Meio Ambiente, na gestão da ministra Marina Silva (PV/AC).
} 
sustentação do status e das informações desses especialistas, tiveram que negociar constantemente a posição e o conteúdo dessas expertises no decorrer das audiências públicas.

\subsection{A DESCENTRALIZAÇÃO DAS LEIS FLORESTAIS E O DISSENSO NAS INFORMAÇÕES DOS ESPECIALISTAS}

A segunda controvérsia debatida nas audiências, que permite ilustrar essa condição de negociação das expertises, referiu-se à definição dos limites nacionais para as APP's. Essa discussão implicava na proposta polêmica de descentralizar as leis florestais.

A proposta de descentralização das leis florestais surgiu no PL 1.876/99 original e consistia em elaborar um Código Florestal que ditasse apenas normas gerais, permitindo aos estados e municípios legislarem segundo suas particularidades. Essa proposta gerou uma controvérsia entre ruralistas, que defendiam uma maior liberdade aos estados e municípios; e ambientalistas, que argumentavam que essa proposta tentava flexibilizar a lei federal para sujeitar as leis florestais ao poder das oligarquias locais.

Para dar sustentação científica a essa proposta, os ruralistas embasaram-se nos testemunhos dos pesquisadores da EMBRAPA - Floresta que participaram das audiências, enfatizando em seus discursos a importância de se instituir um planejamento ambiental científico que, ao invés de estabelecer parâmetros nacionais para os diferentes biomas, partisse do reconhecimento das especificidades ambientais locais. Dentre os especialistas da EMBRAPA - Floresta apoiados pelos ruralistas, Gustavo Ribas Curcio foi o mais emblemático ao dizer que "as medidas estabelecidas para as APP's dispostas no Código Florestal atual são dados tirados da cartola, sem valor científico" (audiência pública da Câmara, 10/11/2009). Para o pesquisador, esses dados advêm de uma época em que havia um desconhecimento das tensões ecológicas nas APP's que, atualmente, levam em conta especificidades como a disposição e composição do solo, a morfologia local, a declividade da encosta, dentre outros fatores. Portanto, um novo Código Florestal, segundo ele, deveria considerar essas particularidades variáveis de local para local. 
As considerações do pesquisador no decorrer das audiências foram adotadas pelos ruralistas como evidência científica da necessidade de promover a proposta de descentralização das leis florestais. Alguns trechos desses discursos, que demonstram a utilização dos argumentos de Gustavo Curcio pelos ruralistas, são:

Há a questão que o pesquisador da EMBRAPA menciona: não é largura do rio que se tem de discutir, como está hoje no Código Florestal Brasileiro, mas o que está na margem do rio. Nesse caso, deve-se tratar de declividade, profundidade e textura de solo, do que tem ao lado do rio. (Dep. Valdir Colatto - PMDB/SC. Audiência pública da Câmara, 30/03/2010).

O que influencia mais numa área de declividade: beira, barranco de rio ou declividade de morro? Não é o tamanho da lâmina d'água, mas sim fatores que estão no barranco. Quais são eles? Espessura do solo, declividade, textura, se argiloso ou arenoso, e a profundidade do solo. Esse é um estudo da EMBRAPA. Mais importante do que a largura do rio é a fragilidade do seu barranco. (Nelson Ananias Filho - Representante da Confederação Nacional da Agricultura, CNA. Audiência pública da Câmara, 03/11/2009).

O especialista em florestas da EMBRAPA disse aqui que as APP's, como estão na lei, são tiradas da cartola. Não pode a mata ciliar ter como base a largura do rio. Tem que ter como base a natureza do terreno, da encosta, se é curva, se é plana, a declividade, o clima, a profundidade do terreno, tipo de solo. Ele disse que isso não é feito (Dep. Aldo Rebelo - PCdoB/SP, Audiência pública da Câmara, 24/11/2009) ${ }^{11}$.

Através de um segundo deslocamento dessas informações nos discursos, buscou-se unir a necessidade de instituir o planejamento ambiental local à proposta de descentralização das leis florestais.

Propomos o pacto Ambiental Federativo Descentralizado. O que é isso? A União faz normas e os estados fazem sua legislação específica. Estes têm que buscar solução através do planejamento técnico de como ocupar o território (Dep. Valdir Colatto - PMDB/MG, Audiência pública da Câmara, 02/03/2010).

Acho que tem de descentralizar, dar autonomia para os estados de acordo com as suas peculiaridades, baseado no zoneamento agrícola, sempre com estudo técnico-científico. Não é a largura do rio que tem de definir a largura da mata ciliar, mas sim a declividade da encosta e o solo. (Dep. Celso Maldaner - PMDB/SC, Audiência pública da Câmara, 11/12/2009).

Competência deve ser dos estados de legislar sobre APP. Por quê? Porque os estados conhecem suas peculiaridades, como o tipo de relevo, clima, solo. Aí eles poderiam estabelecer, de acordo com a ciência, os limites que devem ser preservados para cada área, para cada situação. (Assuero Doca Veronez - Presidente da Federação da Agricultura e Pecuária do Estado do AC, Audiência pública da Câmara, 25/02/2010).

${ }^{11}$ Destaca-se que, apesar do deputado Aldo Rebelo (PCdoB/SP) formalmente não fazer parte da banca ruralista no Congresso, na tramitação do novo Código Florestal, ele foi favorável às propostas dos ruralistas, dentre elas a de descentralização das leis florestais (MIGUEL, 2013, p. 115). 
A contestação dessa argumentação ocorreu nos discursos de opositores da bancada ruralista como, por exemplo, do deputado federal Ivan Valente (PSOL/SP) e do pesquisador da ESALQ/USP, Paulo Kageyama. Estes opositores dirigiram argumentos que contestaram o caráter de "evidência científica" dessas informações, bem como colocaram em cheque o status de expert conferido aos pesquisadores da EMBRAPA - Floresta.

Sobre a definição dos limites das APP's, de forma semelhante ao que foi discutido na controvérsia anterior, também foi utilizado o recurso estratégico de enfraquecer a sustentação científica das propostas políticas através do uso de uma contra argumentação científica. Paulo Kageyama, por exemplo, contestou as informações de Gustavo Ribas Curcio que "circulavam" pelas audiências mencionando pesquisas realizadas por ele e outros pesquisadores da USP a respeito dos parâmetros das APP's dispostos no Código Florestal:

\begin{abstract}
Falando da mata ciliar ou da APP sempre se pergunta: a mata ciliar tem largura cientificamente bem definida? A pesquisadora Maria José Brito Zakia queria questionar se a largura de 30 metros, por exemplo, de rios até 10 metros, tinha sentido. Muito embora tenham ocorrido aparentes contradições, a largura da área ciliar, pelo estudo, foi em média 30 metros ou igual à lei. Ela se frustrou porque queria dizer que aquela área era totalmente arbitrária. E realmente, em média, eram 30 metros. Isto é, meros 30 metros de largura não podem ser tirados da cartola; eles têm alguma razão de ser. (Paulo Kageyama - ESALQ/USP. Audiência Pública da Câmara, 01/12/2009. Grifo nosso).
\end{abstract}

Nesse dissenso entre as informações científicas de Curcio e Kageyama, verifica-se novamente que há "Ciência" para sustentar ambos os lados do conflito, fato que colabora para tornar a controvérsia cientificamente irredutível. Nesse sentido, ao contrário do que esperavam os parlamentares, "trazer a ciência para o debate" não resultou na produção de um consenso, mas acirrou ainda mais a disputa.

Nessa condição de embates inconciliáveis, outros recursos foram utilizados com a finalidade de desacreditar a expertise contrária. Dentre eles, atacar o status científico do especialista ao acusá-lo de parcialidade em seu aconselhamento.

$\mathrm{Na}$ audiência pública da Câmara em que Gustavo Ribas Curcio expôs seus argumentos, o deputado Ivan Valente (PSOL/SP) estava presente e tentou valer-se desse recurso levantando a seguinte questão:

Eu quero perguntar ao Sr. Gustavo o seguinte: uma matéria publicada no jornal O Estado de São Paulo traz a manchete: "Produtores e EMBRAPA Floresta criam rede para pesquisar áreas protegidas”. É um acordo entre a 
CNA e a EMBRAPA. Você poderia depois me explicar o objetivo disso? Os senhores estão contratados pela Confederação Nacional da Agricultura? (Dep. Ivan Valente - PSOL/SP, 10/11/2009).

Através desse questionamento, o deputado do PSOL colocou em dúvida a credibilidade das informações trazidas pelo especialista da EMBRAPA e pôs em risco a legitimidade de sua posição de expert ao insinuar que o Conselho Nacional da Agricultura (CNA) "encomendou" as pesquisas feitas pela EMBRAPA - Floresta ${ }^{12}$. Nota-se, portanto, que nas negociações das controvérsias públicas que envolvem tomadores de decisão e especialistas, além da estratégia de combater expertises com expertises, tentar anular a credibilidade do especialista adversário, isto é, destituí-lo de seu status, é um recurso possível. Isso novamente demonstra que a legitimidade, validade, posição e conteúdo das expertises, no âmbito das arenas públicas, estão sempre em risco e sujeitas a constante negociação.

\section{CONSIDERAÇÕES FINAIS}

Esse artigo buscou indicar que, nas atuais condições em que as decisões públicas são discutidas, definir as alternativas políticas é algo que está relacionado à negociação pública das expertises. Demonstrou-se, através do estudo de caso das audiências públicas do Código Florestal, que a participação de especialistas nessas arenas foi condicionada por diversos fatores que influenciaram na escolha dos participantes e no andamento das deliberações. Estes fatores, alguns deles já apontados por Rifkin e Martin (1997), foram: a prerrogativa da seleção dos convidados pelos parlamentares, o desenho institucional das audiências públicas, a natureza do tema discutido, os grupos para os quais os especialistas falaram e o uso feito de suas informações em diferentes momentos das discussões.

A análise das interações entre tomadores de decisão e especialistas indicou que, no decorrer dos debates, não é possível reconhecer de um lado as políticas e

12 A essa provocação, Gustavo Ribas Curcio respondeu: "nós fomos buscar financiamentos, independente de ser A, B ou C. Estamos buscando e conseguimos financiamento pela CNA. Onde será buscado esse dinheiro eu não sei. A EMBRAPA buscou financiamento para fazer de forma sistemática, no Brasil inteiro, pesquisas de erosão em beira de rio" (audiência pública da Câmara, 10/11/2009). O projeto mencionado na discussão é o Projeto Biomas, mais informações em: http://www.projetobiomas.com.brl. Acesso em: 16/04/2013. 
do outro as expertises. Ao contrário das expectativas iniciais dos parlamentares, a introdução de especialistas para tratar de forma objetiva os impasses entre produtores e ambientalistas não ocorreu devido à dinâmica das discussões nas arenas públicas. Nesses espaços, a constante construção e contestação da credibilidade dos especialistas, assim como do caráter científico de seus argumentos, fez com que as linhas demarcatórias entre políticas e expertises acabassem sendo "borradas", sem que houvesse um efetivo aconselhamento objetivo das decisões (JASANOFF, 1987, 1990).

Essa condição, na qual predominam as controvérsias, suscita importantes questões aos gestores, pesquisadores e à sociedade de um modo geral. Como alcançar condições mais adequadas para tratar de assuntos que envolvem uma gama de opiniões conflitantes e versões contraditórias dos mesmos problemas que requerem nossa atenção e deliberação? Como relacionar essas versões a fim de incorporá-las para obter uma decisão adequada a certas urgências? Como fazer isso sem ameaçar os valores da democracia? Eis alguns dos desafios lançados àqueles que procuram pensar em um modelo de tomada de decisão que consiga lidar com a ampliação das discussões públicas em assuntos que exigem o parecer de especialistas.

\section{REFERÊNCIAS}

BECK, U. Sociedade do Risco: Rumo a uma outra modernidade. 1ª ed. São Paulo: Editora 34, 2010.

BROWN, M.K et al. 2005. Representation, Expertise, and the German Parliament: a comparison of three advisory institutions. In MAASEN, et al. Democratization of Expertise? Springer, Netherlands, 2005, p. 81-100.

CESARINO, L, N. Nas fronteiras do "Humano": os debates britânico e brasileiro sobre pesquisas com embriões. MANA, 2007, 13(2): 347-380.

FOUCAULT, M. Microfísica do poder. Rio de Janeiro: Graal, 1982.

GIERYN, T. F. Boundary-work and the demarcation of science from no-science: Strains an interests in professional ideologies of scientists, Ame. Sociological Rev., vol. 48, 1983, p. 781-795. 
JASANOFF, S. Contested Boundaries in Policy-Relevant Science. Social Studies of Science, London, Sage, v. 17, n. 17, n. 2, may, 1987, p. 195-230.

. The Fifth Branch: science advisers as policymakers. Cambridge,

Harvard University Press, 1990.

LAKOFF, S. A. Knowledge and power. New York: Free Press, 1966.

MIGUEL, J. Da fronteira florestal aos limites da ciência: um estudo sobre a participação de especialistas nas audiências públicas para a elaboração do novo Código Florestal brasileiro. Dissertação de Mestrado (Política Científica e Tecnológica) Campinas, Instituto de Geociências, UNICAMP, 2013.

MEYNAUD, J. Technocracy. New York: Free Press, 1969.

MORIN, E. A ciência com consciência. $3^{a}$ ed. Rio de Janeiro: Bertrand Brasil, 1999.

MARCUSE, H. A ideologia da sociedade industrial. $5^{\underline{a}}$ ed. Rio de Janeiro: Zahar, 1979.

NELKIN, D. Scientific knowledge, public policy and democracy. Sage, 1979.

NOWOTNY, H. Transgressive Competence: The Narrative of Expertise. European Journal of Social Theory, 3:5, Sage, 2000.

RIFKIN, W.D; MARTIN, B. Negotiating expert status: who gets taken seriously. IEEE Technology and Society Magazine, vol. 16, n. 1, Springer, 1997, p. 30-39.

WEINGART, P. What's New in Scientific Advice to Politics? In MAASEN, S. et al. Democratization of Expertise? Springer, Netherlands, 2005, p. 01-19.

WEBER, M. Economia e sociedade. $3^{\text {a }}$ ed., vol. 1. Brasília: Ed. UnB, 1994. 